\title{
Multifunctional Materials Based on Tetrathiafulvalene Derivatives with Binding Sites for Metal Ions
}

\author{
Stefan Dolder, Shi-Xia Liu*, and Silvio Decurtins
}

\begin{abstract}
Tetrathiafulvalene (TTF) and its derivatives are very well known as reversible, stable two-electron donors and they have found widespread use in the field of organic conductors and superconductors. Further, during the last decades, developments in synthetic TTF chemistry have enabled the use of TTF and its derivatives as versatile building blocks in new fields of materials and supramolecular chemistry. This brief review relates some recent advances that have been achieved by combining the redox and conducting properties of TTF with other functionalities, such as magnetism or optical properties. A variety of TTF-based ligand systems and their metal complexes are presented.
\end{abstract}

Keywords: Coordination chemistry · Dithiolenes - Organic conductors and superconductors · Redox switches · Tetrathiafulvalene (TTF)

\section{Introduction}

Heterocycles form by far the largest chemical class in organic chemistry and are of immense importance industrially and biologically. More specifically, organic compounds possessing a high degree of conjugation are ideal materials for advanced electronic applications in the emerging field of molecular electronics [1]. Within this context, a prominent prototype of heterocyclic compounds is tetrathiafulvalene (TTF) and since the discovery of the first organic conductor, namely TTFCl in 1972 [2], and also the metallic behavior in the charge-transfer complex TTF-TCNQ (TC$\mathrm{NQ}=$ tetracyano- $p$-quinodimethane) [3],
${ }^{*}$ Correspondence: Dr. S.-X. Liu

University of Bern

Department of Chemistry and Biochemistry

Freiestrasse 3

$\mathrm{CH}-3012$ Bern

Tel.: +41316314296

Fax.: +41316313995

E-Mail: liu@iac.unibe.ch
TTF has become one of the most studied heterocyclic systems [4]. Consequently, TTF and its derivatives, on account of their unique $\pi$-donor properties, are successfully used as versatile building blocks for chargetransfer salts, giving rise to a multitude of organic conductors and superconductors [5].

The key property of the electron-rich TTF unit is its ability to act as a unique $\pi$-electron donor. TTF can be sequentially and reversibly oxidized to the thermodynamically stable radical cation $\mathrm{TTF}^{\circ+}$ and dication $\mathrm{TTF}^{2+}$. The contribution from $6 \pi$-electron heteroaromaticity in the $1,3-$ dithiolium cations explains the relatively low oxidation potentials and stability of the oxidized states (Fig. 1) [6].

In the solid state, TTF derivatives readily form highly ordered stacks or twodimensional sheets, which are stabilized by intermolecular $\pi-\pi$ interactions and nonbonded chalcogen-chalcogen interactions. These short contacts allow by means of chalcogen $\pi$-orbital overlap the formation of a band structure. Consequently, partial oxidation of the TTF species in the stacks generates, due to the partially filled conduction band, the charge carriers for the conducting properties. As a result, conducting charge-transfer salts are composed of arrays of donor and acceptor species, one or both of which must be a radical ion. As a case in point for a TTF derivative, Fig. 2 illustrates a superconducting charge-transfer system which exhibits a strong network of inter-stack, as well as intra-stack seleniumselenium interactions [7].

Progress in synthetic TTF chemistry [4][5] has enabled the preparation of elaborate molecular architectures and, in recent years, TTF has been incorporated into a number of molecular and supramolecular systems, such as cyclophanes, catenanes, rotaxanes, dendrimers, etc. [8]. Especially the development of TTF-based ligands for the coordination of metal centers has been a subject of growing interest. Complexation of metal ions to the TTF unit is seen as a promising strategy for the construction of materials that combine two or more physical properties, such as electrical conductivi-

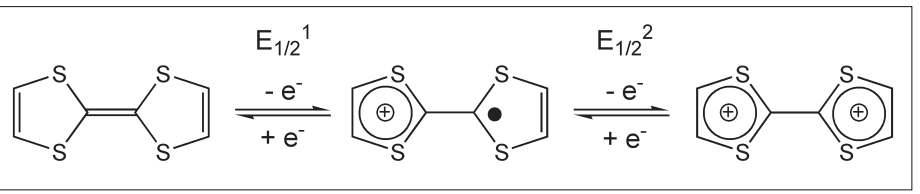

Fig. 1. Reversible redox states of TTF: $\mathrm{E}_{1 / 2}{ }^{1}=0.34 \mathrm{~V}, \mathrm{E}_{1 / 2}{ }^{2}=0.73 \mathrm{~V} v s \mathrm{Ag} / \mathrm{AgCl}$ in $\mathrm{MeCN}$ [6] 


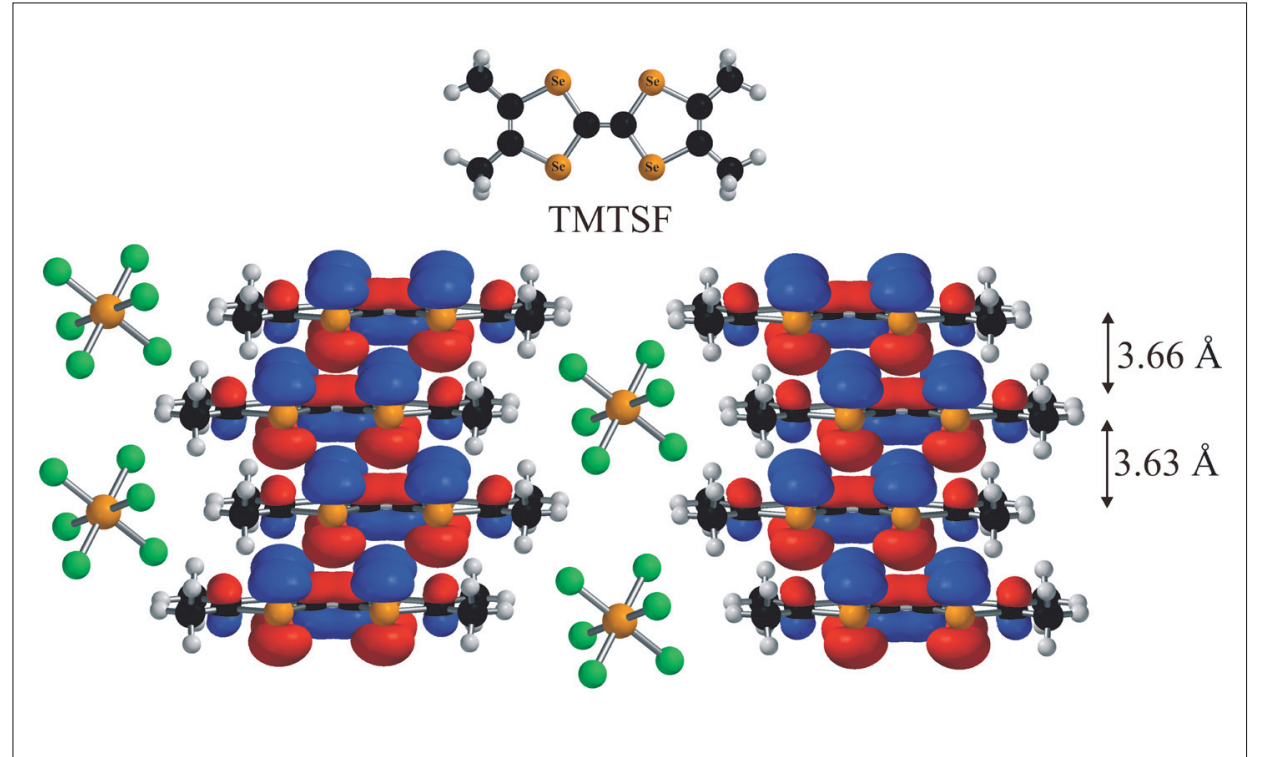

Fig. 2. Layered structure of $(\mathrm{TMTSF})_{2}{ }^{+\bullet} \mathrm{PF}_{6}{ }^{-}$which is a superconductor under pressure $(\mathrm{TMTSF}=$ tetramethyltetraselenafulvalene). The overlap of the selenium $\pi$-orbitals along the stacks forms a conduction band with a width of ca. $1 \mathrm{eV}[7]$.

a
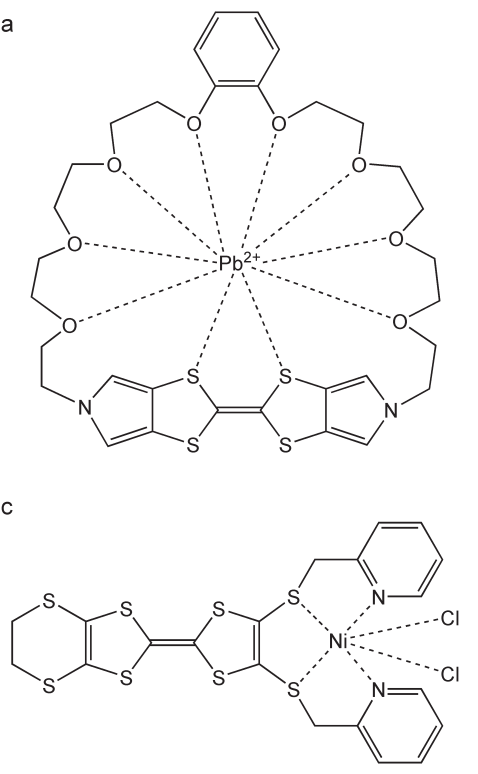

b

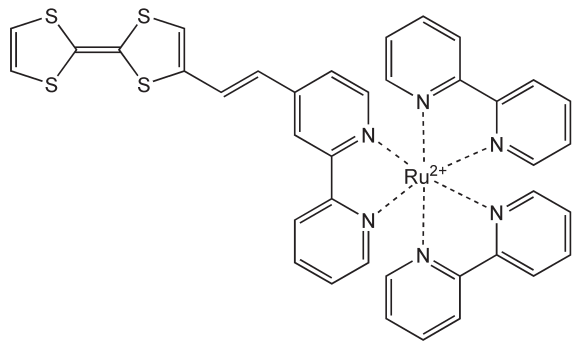

d

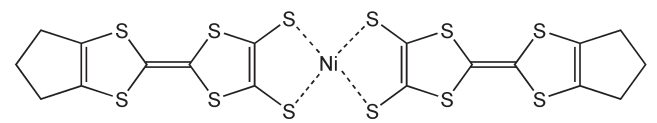

valene (BEDT-TTF) layers and ferromagnetic oxalate-based bimetallic layers, has been realized [16]. However, in this specific case, no substantial $\pi$-d interactions could be determined.

Therefore, in order to achieve stronger $\pi$-d interactions, the strategy of direct coordination of magnetic metal ions to TTFbased ligands has recently been developed [13] [17]. Along this line of research, TTF complexes with paramagnetic metal ion centers are prepared, which are, in a second step, chemically or electrochemically oxidized. In the case of partial oxidation and favorable stacking of the TTF metal complexes, a material with strong $\pi$-d-interactions $\left(\mathrm{J}_{\pi-\mathrm{d}}\right)$ between the mobile $\pi$-electron carriers of the conduction band and the electron spins of the metal ion centers is expected to be formed.

In our research group we are following a synthetic strategy to link paramagnetic and/or photoactive transition metal ions directly to the skeleton of TTF units by flexible, chelating $\mathrm{S}$ - and $\mathrm{N}$-donor binding groups, such as sulfanylmethylpyridine or -pyrazine groups (Fig. 3c) [18]. Thereby, with these tetradentate TTF-ligands, $\mathrm{Co}$ (II), $\mathrm{Ni}(\mathrm{II}), \mathrm{Zn}(\mathrm{II})$ and $\mathrm{Ru}(\mathrm{II})$ complexes have been prepared [13][19] and, e.g. in the case of a Ni(II) complex, a chemical oxidation by iodine has successfully been achieved [20]. As a result, a $\mu$-dichloro bridged dinuclear $\mathrm{Ni}(\mathrm{II})$ complex emerged which bears four spin centers, namely two with electron spin values of $\mathrm{S}=1$ from the $\mathrm{Ni}(\mathrm{II})$ ions and two with $S=1 / 2$ from the $\mathrm{TTF}^{\bullet+}$ radicals (Fig. 5a). A detailed analysis revealed that the magnetic exchange coupling between the two $\mathrm{Ni}(\mathrm{II})$ ions is of ferromagnetic nature, whereas the $\mathrm{TTF}^{\bullet+}$ radicals exhibit a weak antiferromagnetic interaction towards the central core. However, due to steric reasons, this actual molecular geometry is not yet optimal for reasonable conducting properties. Additionally, it is worth mentioning that the oxidation of this functionalized ligand system with $\mathrm{Cu}\left(\mathrm{ClO}_{4}\right)_{2}$ produces a formerly unknown 3,3'-bithiazolo[3,4-a]pyridinium ring system (Fig. 5b) [21]. This observation illustrates that specifically functionalized TTFs can also open access to new synthetic reaction pathways.

ty, magnetic interactions and photophysics, in a synergistic way. The first TTF-based ligands and their metal complexes were already prepared in the 1980s [9]. Since the 1990s, systems such as redox-switchable TTF crown compounds [10], TTF-based photo-redox or electrochromic switches [11] and single-component molecular conductors [12] have been prepared. Overall, a large variety of TTF-based ligands has proven to be of particular interest because of their multiple coordination abilities to different metal ions in combination with their unique redox properties (Fig. 3).

\section{TTF-Based Compounds with $\pi$-d Interactions: Magnetic Molecular Conductors}

The main idea is to form inorganic/ organic hybrid materials with the aim to establish interactions between the mobile $\pi$-electrons of organic conducting TTF layers and localized electron spins of paramagnetic centers in inorganic layers (Fig. 4) [14][15]. For this purpose different strategies are explored. For instance, the preparation of a hybrid material exhibiting both conducting bis(ethylenedithio)tetrathiaful-

\section{Perspectives: Merging TTF and Phthalocyanine or Hexaazatriphenylene Chemistry}

To trace some recent developments in TTF chemistry, we want to emphasize that there is keen interest in the synthesis and study of supramolecular systems involving the covalent linkage of TTFs to porphyrins [22a], calix[4]pyrroles [22b] and calix[4]arenes [22c] etc. Such ensembles are mainly investigated for their multi- 


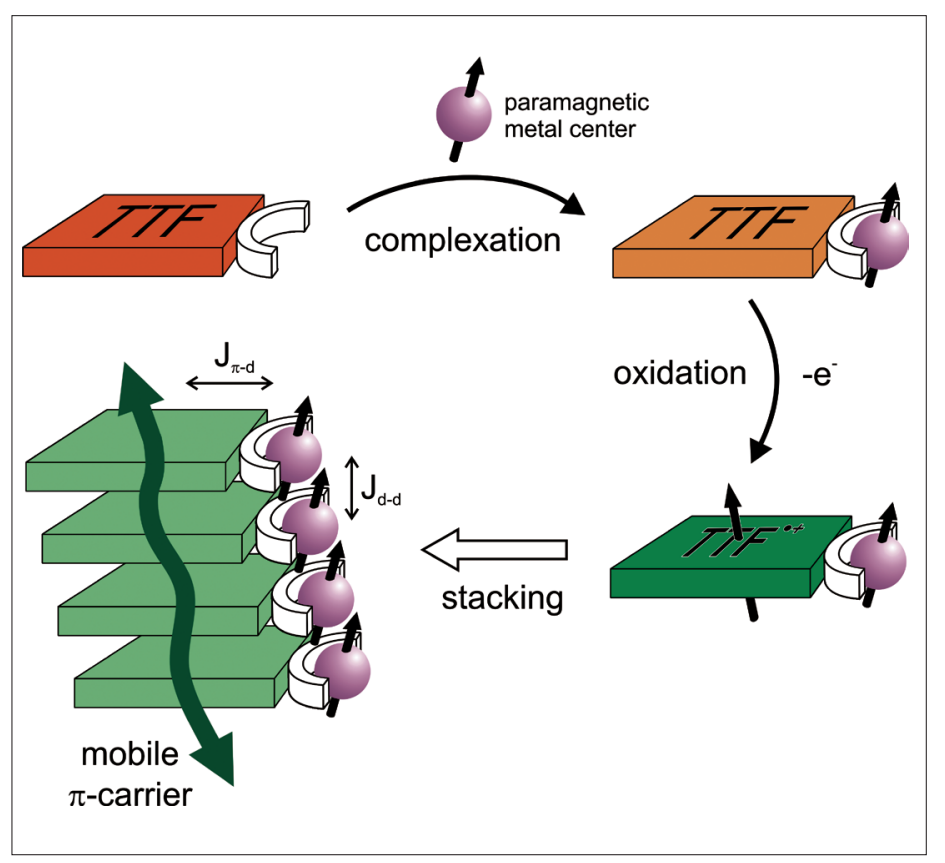

Fig. 4. Strategy for the construction of multifunctional materials combining conducting properties of TTF-based ligands and magnetic properties of paramagnetic metal ion centers

a

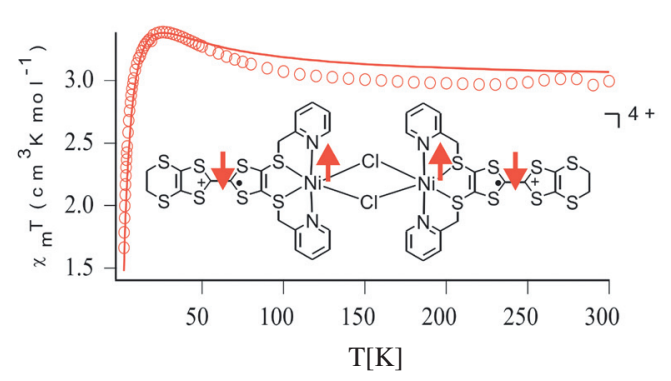

Fig. 5. a) Magnetic exchange interactions between $\mathrm{Ni}\left(\right.$ II) ions and radical TTF${ }^{\bullet+}$ ligands in a $\mu$-dichloro bridged dinuclear Ni(II) complex [20]; b) Formation of a 3,3'-bithiazolo[3,4-a]pyridinium ring system by $\mathrm{Cu}(\mathrm{II})$ oxidation of a TTF-ligand [21]

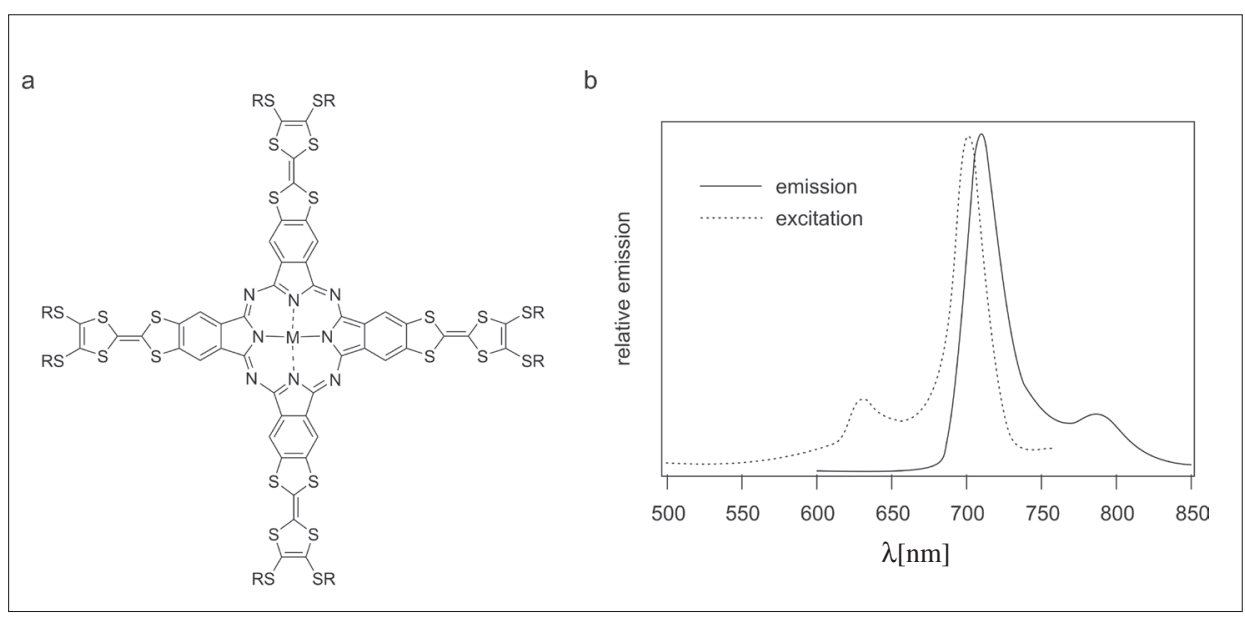

Fig. 6. a) The redox-active TTF-annulated MPc [25]; b) Excitation and emission spectra of the oxidized form $\mathrm{MPC}\left(\mathrm{TTF}^{\bullet+}\right)_{4}$ in THF; the emission is totally quenched for the neutral form MPc-(TTF) ${ }_{4}[25 a, b]$ electron redox activities and photophysical properties. Similarly, to give a further example about the investigation of new structural modifications of such entities, a self-assembling ability has been demonstrated in the case of tetrakis(tetrathiafulvalene-crown-ether)-substituted metal-free and copper phthalocyanines, whereby micrometer-long and nanometer-wide helical tapes could be prepared [23]. Other notable examples concern the synthesis of model systems to study charge-recombination dynamics, for instance in TTF- $\mathrm{C}_{60}$ dyads [24]. In the context of these new developments, a clear-cut case achieved in our laboratory is shown by the direct annulation of four TTF units to a phthalocyanine core [25]. Fig. 6a shows the novel redox-active, fused donoracceptor molecule which exhibits in the cyclic voltammogram two reversible fourelectron oxidation waves and one reversible one-electron reduction wave, corresponding to the oxidation of four TTF units (HOMO) and the reduction of the phthalocyanine core (LUMO), respectively. Interestingly, a very efficient fluorescence switching by oxidation of the non-fluorescent neutral molecule to the fluorescent tetracation is observed; the emission is quenched in the neutral state due to the charge-transfer state characterized by one TTF unit oxidized to $\mathrm{TTF}^{\bullet+}$ and the Pc unit reduced to $\mathrm{Pc}^{\bullet-}$ (Fig. $6 b)$.

Another striking example concerns the annulation of three TTF units to a hexaazatriphenylene (HAT) core [26]. Fig. 7 shows this planar $\pi$-conjugated heteroaromatic molecule which combines an electron-deficient $\pi$-system as an acceptor unit with three TTF donor units; thereby, an extended redox-active donor-acceptor system with intriguing molecular tri-star geometry emerges.

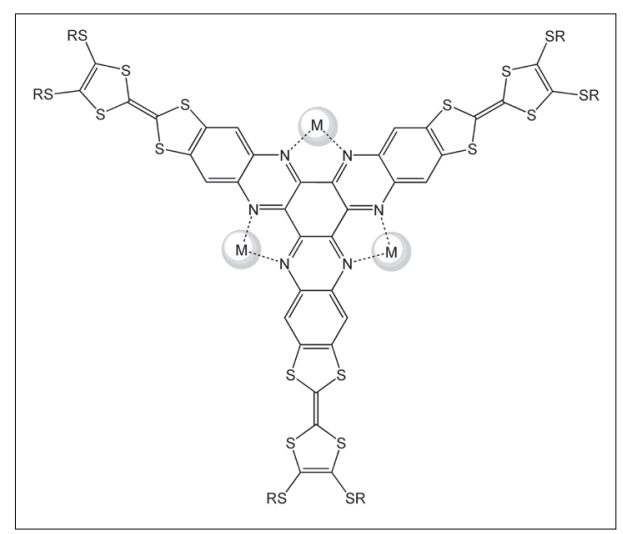

Fig. 7. The redox-active TTF annulated HAT molecule bearing three chelating metal ion binding sites [26]

Note that this compound bears additionally three chelating coordination sites for binding metal ions. This specific topology of the coordination sites renders HAT 
an especially interesting building block for creating self-assembled extended coordination frameworks.

Finally, in Fig. 8, another recent result of our synthetic efforts is shown with the planar TTF-fused dipyridophenazine molecule [27]. In view of the concept described above (see Fig. 4), this donor-acceptor molecule represents an ideal candidate for realizing a new class of inorganic/organic hybrid materials.

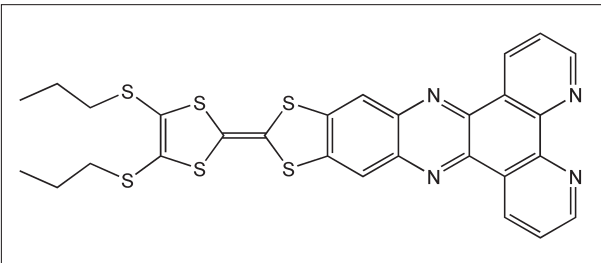

Fig. 8. A new planar TTF-fused dipyridophenazine molecule bearing a chelating metal ion binding site [27]; note the equivalence to the concept presented in Fig. 4

\section{Conclusions}

Since the synthesis of the radical cation bis-1,3-dithiolium, $\mathrm{TTF}^{\bullet+}$, in 1970, and the use of the singular 'electron rich' olefin tetrathiafulvalene to form charge-transfer complexes, TTF has remained the most studied heterocyclic system. Much creative effort is still ongoing today and a recent review of this research field [28] highlights the progress of these disciplines at the organic - inorganic - materials and physics interface. Expectations are also high in the search for new supramolecular ensembles which incorporate the redox-active TTF as donor part for multifunctional molecular materials.

\section{Acknowledgement}

Financial support from the Swiss National Science Foundation (Grant No. 200020107589) and COST action D31 is gratefully acknowledged.

Received: March 15, 2006

[1] R.L. Carroll, C.B. Gorman, Angew. Chem. Int. Ed. 2002, 41, 4378.

[2] F. Wudl, D. Wobschall, E. Hufnagel, J. Am. Chem. Soc. 1972, 94, 670.

[3] J. Ferraris, D.O. Cowan, V.V. Walatka, J.H. Perlstein, J. Am. Chem. Soc. 1973, 95, 948 .

[4] a) J. Yamada, T. Sugimoto, Eds. 'TTF Chemistry. Fundamentals and applications of Tetrathiafulvalene' Springer Verlag, Berlin, 2004; b) T. Otsubo, K. Takimiya, Bull. Chem. Soc. Jpn. 2004, 77, 43; c) P. Frère, P. Skabara, Chem. Soc. Rev. 2005, 34, 69.

[5] P. Batail in 'Molecular Conductors', Chem. Rev. 2004, 104, 4887.
[6] J.O. Jeppesen, M.B. Nielsen, J. Becher, Chem. Rev. 2004, 104, 5115.

[7] M.R. Bryce, Chem. Soc. Rev. 1991, 20, 355.

[8] J.L. Segura, N. Martín, Angew. Chem. Int. Ed. 2001, 40, 1372.

[9] a) T. Otsubo, F. Ogura, Bull. Chem. Soc. Jpn. 1985, 58, 1343; b) G. Matsubayashi, K. Yokoyama, T. Tanaka, J. Chem. Soc. Dalton. Trans. 1988, 3059

[10] a) F. Le Derf, M. Mazari, N. Mercier, E. Levillain, G. Trippé, A. Riou, P. Richomme, J. Becher, J. Garín, J. Orduna N. Gallego-Planas, A. Gorgues, M. Sallé, Chem. Eur. J. 2001, 7, 447; b) J.O. Jeppesen, J. Becher, Eur. J. Org. Chem. 2003 , 3245.

[11] a) M.R. Bryce, Adv. Mater. 1999, 1, 11; b) C. Wang, A.S. Batsanov, M.R. Bryce, Chem. Commun. 2004, 578.

[12] H. Tanaka, Y. Okano, H. Kobayashi, W. Suzuki, A. Kobayashi, Science 2001, 291, 285.

[13] S.-X. Liu, S. Dolder, P. Franz, A. Neels, H. Stoeckli-Evans, S. Decurtins, Inorg. Chem. 2003, 42, 4801.

[14] a) K. Nagayoshi, Md.H. Kabir, H. Tobita, K. Honda, M. Kawahara, M. Katada, K. Adachi, H. Nishikawa, I. Ikemoto, H. Kumagai, Y. Hosokoshi, K. Inoue, S. Kitagawa, S. Kawata, J. Am. Chem. Soc. 2003, 125, 221; b) E. Coronado, P. Day, Chem. Rev. 2004, 104, 5419.

[15] a) R. Kanehama, M. Umemiya, F. Iwahori, H. Miyasaka, K. Sugiura, M. Yamashita, Y. Yokochi, H. Ito, S. Kuroda, H. Sishida, H. Okamoto, Inorg. Chem. 2003, 42, 7173; b) L. Ouahab, T. Enoki, Eur. J. Inorg. Chem. 2004, 5, 933.

[16] E. Coronado, J.R. Galán-Mascarós, C.J. Gómez-García, V. Laukhin, Nature 2000 , 408, 447.

[17] a) F. Setifi, L. Ouahab, S. Golhen, Y. Yoshida, G. Saito, Inorg. Chem. 2003, 42, 1791; b) J. Massue, N. Bellec, S. Chopin, E. Levillain, T. Roisnel, R. Clérac, D. Lorcy, Inorg. Chem. 2005, 44, 8740; c) C. Jia, S.-X. Liu, C. Ambrus, A. Neels, G. Labat, S. Decurtins, Inorg. Chem. 2006, 45 , 3152

[18] a) S.-X. Liu, S. Dolder, M. Pilkington, S. Decurtins, J. Org. Chem. 2002, 67, 3160 b) S.-X. Liu, S. Dolder, E.B. Rusanov, H. Stoeckli-Evans, S. Decurtins, C. R. Chimie 2003, 6, 657.

[19] a) S. Dolder, S.-X. Liu, G. Labat, S. Decurtins, J. Phys. IV France 2004, 114, 683; b) S.-X. Liu, A. Neels, H. Stoeckli-Evans, S. Decurtins, Phosphorus, Sulfur and Silicon 2005, 180, 1469

[20] S.-X. Liu, C. Ambrus, A. Neels, S. Decurtins, Inorg. Chem. 2006, submitted.

[21] S.-X. Liu, C. Tanner, A. Neels, S. Dolder, S. Leutwyler, P. Renaud, P. Bigler, S. Decurtins, Angew. Chem. Int. Ed. 2004, 43 , 4737

[22] a) H. Li, J. O. Jeppesen, E. Levillain, J. Becher, Chem. Commun. 2003, 846; b)
K. A. Nielsen, W.-S. Cho, J.O. Jeppesen, V.M. Lynch, J. Becher, J.L. Sessler, J. Am. Chem. Soc. 2004, 126, 16296; c) B.T. Zhao, M.-J. Blesa, N. Mercier, F. Le Derf, M. Sallé, J. Org. Chem. 2005, 70, 6254.

[23] J. Sly, P. Kasák, E. Gomar-Nadal, C. Rovira, L. Górriz, P. Thordarson, D.B. Amabilino, A.E. Rowan, R.J.M. Nolte, Chem. Commun. 2005, 1255.

[24] S. Handa, F. Giacalone, S.A. Haque, E. Palomares, N. Martin, J.R. Durrant, Chem. Eur. J. 2005, 11, 7440.

[25] a) C. Loosli, C. Jia, S.-X. Liu, M. Haas, M. Dias, E. Levillain, A. Neels, G. Labat, A. Hauser, S. Decurtins, J. Org. Chem. 2005 , 70, 4988; b) S. Delahaye, C. Loosli, S.X. Liu, S. Decurtins, G. Labat, A. Neels, A. Loosli, T. Ward, A. Hauser, Adv. Funct. Mater. 2006, 16, 286; c) C.A. Donders, S.-X. Liu, C. Loosli, L. Sanguinet, A. Neels, S. Decurtins, Tetrahedron 2006, $62,3543$.

[26] C. Jia, S.-X. Liu, C. Tanner, C. Leiggener, L. Sanguinet, E. Levillain, S. Leutwyler, A. Hauser, S. Decurtins, Chem. Commun. 2006, 1878.

[27] C. Jia, S.-X. Liu, C. Tanner, C. Leiggener, A. Neels, L. Sanguinet, E. Levillain, S. Leutwyler, A. Hauser, S. Decurtins, J. Am. Chem. Soc. 2006, submitted.

[28] Special Issue on Molecular Conductors, Chemical Reviews 2004, 11. 